\title{
Slow Fire: \\ Serial Thinking and Hardy's Genres of Induction
}

\author{
DANIEL WILLIAMS
}

Early in Thomas Hardy's first novel, Desperate Remedies (1871), an architect in training meets a young woman by accident. Love at first sight turns out to involve a conundrum, notorious in the history of philosophy, about drawing predictions from serial events: will the sun rise tomorrow? Between Edward Springrove and Cytherea Graye appears "one of those unaccountable sensations which carry home to the heart . . . by something stronger than mathematical proof, the conviction, 'A tie has begun to unite us" (Hardy [1871] 2003, 32). Yet on parting, Edward is left with "a hopeless sense of loss akin to that which Adam is said by logicians to have felt when he first saw the sun set, and thought, in his inexperience, that it would return no more" (33).

Hardy sketches two modes of judgment under uncertainty here, corresponding to the poles of what I call "serial thinking," an approach to representation and cognition that emphasizes repetition, enumeration, and aggregation. ${ }^{1}$ The first mode blurs the discrete boundaries of numbers and subjects to register an "unaccountable" emotional link. The second, formulated in the negative, marks the clear separation between what the novel sees as a single or "cardinal event" (10) and the (hoped-for) emergence of an ordinal pattern. One mode is affective, tactile, inchoate; the second rational, numerical, predictive. The argument that follows turns on the difference between these modes, their connections to problems of generic classification, and the shared claims of novelists and "logicians" to their exposition.

1. As I discuss below, "serial thinking" is animated by the concept of "series" in the work of the nineteenth-century logician John Venn. The term is unrelated to serialized publication. 
Both groups have historically had an interest in the sun's rising, a stock example in branches of philosophy and mathematics that deal with probable inferencewith how single instances can be grouped together in aggregate classes, thereby furnishing a basis for judgment in putatively similar cases. Hardy might have found the sun's rising stated as an exemplary problem of induction in texts by Joseph Butler ([1736] 1740, vi), David Hume ([1743] 2000, 24), or John Stuart Mill ([1843] 1973, 1:550-51). But his specific allusion is drawn from a primer on logic that he owned and annotated. The Art of Reasoning, by the schoolmaster Samuel Neil $(1853,3)$, would have appealed to a young architect from rural Dorset struggling to become an author, given its promotion of reason in "the operations of the farm, in the labours of . . the lathe, the sledge-hammer," and "in the pursuit of literature." Citing Samuel Taylor Coleridge's Table Talk, Neil's example spotlights different styles of assessing evidence: "Suppose Adam watching the Sun sinking under the horizon for the first time; he is seized with gloom and terror, relieved with scarce a ray of hope of ever seeing the glorious light again. The next evening when it declines, his hopes are stronger, but mixed with fear; and even at the end of 1000 years, all that a man can feel, is hope and an expectation so strong as to preclude anxiety" (Coleridge 1990, 1:244-45, quoted in Neil $1853,98)$. Whether the sun will rise and what fortunes it will bring are weighty propositions for Hardy, who, like Coleridge, found in the sun a quasi-mystical symbol. The type of repetition the solar cycle both enacts and causes is central to Hardy's system of representation. Like the sun's rising, instances of serial thinking and representation can be discrete and numerical or indistinct and tangible. They can include counted events and uncountable shifts, sudden mental bursts and slow material changes. In the first section, I show how Hardy deploys serial representation in Desperate Remedies both in material forms (long-run processes of wear, attrition, and change) and in numerical senses (patterns of counting and aggregation). Serial thinking establishes Hardy's interests in Victorian logic and the novel's congruence with his later output.

These styles of thinking and modes of representation are more than just isolated anticipations of later technique, however. Serial thinking figures a problem, original to the nineteenth century, that connects both logical classes and literary genres. In the second section, I argue that this so-called reference class problem speaks to the curious generic identity of Desperate Remedies (conventionally a sensation novel) and to broader difficulties of genre designation. Hardy's early concern about the groups in, about, and for which he was writing emerges in the 
problem of how classes - whether logical, social, or generic - are decided and redrawn. Alongside serial representations that are both discrete and blurred, the novel enacts in its figures for class thinking a generic identity that is by turns stable and unbalanced, diffident about its membership in a given set. Hardy's intuitions about serial and class thinking, which draw on nineteenth-century logic's decision problems and its discourse of "sets" and "classes" and their "members," can be thus linked to questions of genre, a concept whose intrinsic openness to qualification, exception, and mutability has been productively described in this flexible language. I conclude by connecting these nineteenth-century images for the bounding and blurring of classes to similar figures in recent studies of genre. Considering the deeper historical relationship between generic thinking and the areas of inductive logic and probability that undergird later approaches to genreboth theoretical accounts and empirical studies, often using digital tools - can show how generic dynamism demands methods of reading that collaborate along the explanatory axes of narrative and data.

\section{Serial Thinking: Number and Materiality}

The central event of Desperate Remedies is a fire that consumes the Three Tranters Inn and several adjoining cottages. The Springrove family leases these buildings on lifehold from the owner of the estate, Cytherea Aldclyffe (henceforth Miss Aldclyffe, not to be confused with the younger woman named after her, Cytherea Graye, henceforth Cytherea). The terms of this pivotal event juxtapose the two poles of serial thinking: numerical sequence and material iteration. At the latter pole, the descriptions of its setting establish the inn, a "many-gabled, mediæval building," as a significant site of material accretion and attrition (Hardy [1871] 2003, 117). Hardy highlights a situated knowledge where what appears to be one item of data overlays a long-run blend. The inn's sign shows three worn figures, "the grain of the wood and joints of the boards being visible through the thin paint depicting their forms, which were still further disfigured by red stains running downwards from the rusty nails above" (118). It is a familiar tactic of Hardy to describe the worn and weathered, and moments like these have been seen as straining realism in the depiction of repetitive acts and tactile percepts. ${ }^{2}$

2. See Scarry 1994, 49-90; Ward 2011. 
Such descriptions also have an abstract function: they ask us to reflect on how everyday inferences and predictions rely on individual events that blur into composite states of affairs. Throughout the novel Hardy lavishes attention on repetitions, like this description of a gate outside the law offices of Lincoln's-Inn-Fields: "Rust was the only active agent to be seen there at this time of the day and year. The palings along the front were rusted away at their base to the thinness of wires, and the successive coats of paint . . . had been completely undermined by the same insidious canker, which lifted off the paint in flakes, leaving the raw surface of the iron ... of a staring blood red" (102). Beyond any specific inference we are left with a sense of the significance, almost the vitality of material iteration. In the settings where events occur, there are always details that flag what information could be relevant and how it might be used. The fire takes place against the background of such aggregate representations, the "repetition [that] educates the sensorial agency" (Neil 1853, 13).

Yet at the other pole of serial thinking, the fire is also a failure to take longrun information into account when presented with a short, numerical sequence. On the first evening that Edward's father, Farmer Springrove, checks on a heap of smoldering couch-grass, his "perfectly sound conclusion was, that as long as the heap was not stirred, and the wind continued in the quarter it blew from then, the couch would not flame, and that there could be no shadow of danger to anything, even a combustible substance." On the second evening he looks "less carefully." On the "morning and the whole of the third day [he] still saw the heap in its old smouldering condition; indeed, the smoke was less, and there seemed a probability that it might have to be re-kindled on the morrow," and on the third evening he therefore "glanced at the heap casually and indifferently in passing; two nights of safety seemed to ensure the third" (Hardy [1871] 2003, 166). Not in a Hardy novel, it seems, where grass and thatch suddenly ignite and the "whole row of houses was destroyed." "Each presented itself as one stage of a series, progressing from smoking ruins at the end where the inn had stood, to a partly flaming mass . . . at the other" (177).

The fire happens because Farmer Springrove refers to a series that is brief and discrete - one, two, three - to make a prediction about a continuous process in a world where the weathering of long-run series should have compelled a more cautious approach, as Hardy explains with reference to what "farmers and horticulturalists well know" (167). Hardy's attention to aggregate phenomena adds a more textured surface to examples in the history of inductive logic and 
probability, where inferences are drawn from isolable units like coin tosses (see Hacking 2006). Desperate Remedies mines this tension between the discrete and the continuous. The novel sometimes represents events or judgments in numbered lists (Hardy [1871] 2003, 15-16, 269, 348) and repeats questions or snippets of conversation (295). In addition to this ordinal obsession (first, second, third, and so on are unusually abundant terms), the novel's chapters and subsections are temporally segmented: "The Events of Eight Days," "November the twenty-first," "Four to five, p.m." $(34,154,117)$. Marking time and spatializing it into discrete blocks of reading experience that correspond to "events," these titles inure us to the sense that numbers have an anticipatory, inferential purpose. But the novel also presents a worn, smudged world and indulges in vague descriptors- - "one or two," "two or three," all the way to "six or seven" $(165,118,296)$ - whose inexactness constitutes a reality effect, blurring boundaries between numbers, moments, persons, and classes. These are competing realisms of number, vaguely enumerating the world while scrupulously recording its events, tracking a nebulously slow fire while watching for its distinct ignition. ${ }^{3}$

The way an aggregate series emerges from single events - as it were dissolving the discrete into the continuous - is discussed in one influential work of Victorian logic, John Venn's The Logic of Chance ([1866] 1888; second edition 1876). Given Hardy's inclusion of a character who appears as Venn's namesake in The Return of the Native (1878), I proceed here on the assumptions that he had some familiarity with this work (or reviews thereof) and that this later connection can anyway help clarify the stakes of series in Desperate Remedies. For Venn, probability is a concept that only makes sense in reference to the frequency of events or instances. ${ }^{4}$ The so-called frequency theory determines an event's likelihood as the limit of its frequency of occurrence in a large number of trials. It commits us to a view of probability - and the inferences it affords - as an experiential, material, and mutable domain. The key term in Venn's account is series. Given a class of events — not necessarily in temporal sequence — that "combines individual irregularity with aggregate regularity," a "long succession of instances" will furnish "a numerical proportion, not indeed fixed and accurate at first, but which tends in the long run to become so" (Venn [1866] 1888, 4, 5).

3. I use slow fire to condense the continuous and sudden aspects of serial thinking. In library science the term refers to the material decay of paper.

4. For background to the frequency theory and the shift away from subjective probability, see Hacking 2006, 53-54, 1990; Porter 1986, 71-88. On Venn's contribution, see Eden 1998; Wall 2006. 
Earlier analyses of aggregate phenomena in the episteme that Lorraine Daston (1998, 33-36, 49-111, 218-23) calls "classical probability" see events as tending toward underlying, law-like patterns. At the end of this dispensation, Pierre-Simon Laplace's ([1814] 1902, 19) calculations on the probability of sunrise could thus declare "a bet of 1826214 to one that it will rise again to-morrow." In Venn's more open-ended, empirically motivated view of probability judgments, extending calculations based on games and exact numbers to natural or social series is problematic. Regarding individual units, it requires a "substitution" or "process of idealization," so that unruly cases can be "pruned a little into shape, as natural objects almost always have [to be] before they are capable of being accurately reasoned about" (Venn [1866] 1888, 119-20). This is tantamount "to assuming the expected results" (84; see also 74-95).

Yet despite the looming problem of induction - of the alterable categories in aggregate patterns - we find it difficult to generate probable inferences unless we take "some natural series as a copy," since it is impossible "to construct one mentally which shall permanently imitate the originals" (68). This is necessary, because "our conviction generally rests upon a sort of chaotic basis composed of an infinite number of inferences and analogies of every description, and these moreover distorted by our state of feeling at the time" (126-27). Venn highlights the subjective complexity of empiricism, of how evidence filters through different channels. The "several great streams from which Consciousness gains its knowledge" - as Neil $(1853,62)$ summarizes them in a list repurposed verbatim in Far from the Madding Crowd -include "Intuition, Sensation, Memory, Analogy, Testimony, Probability, Induction” (Hardy [1874] 2000, 12). In this vision of judgment and belief refracted through frequency, inferences can shift "without any conscious alteration of the evidence," like "those alternations of light and dark in a murky foggy day" (Venn 1870, 6).

Or like the pulsing of embers on a clear, dry night. The fire in Desperate Remedies, that is to say, tests models of evidence and judgment, setting the numerical and sequential against the material and felt, the countable ignition against the indefinite smoldering. The fire is an object lesson in how circumstances and events are drawn together in causal steps. It speaks to the novel's investment in "the idea of sequence as form" to the point of being "a parody of sequence" (Bayley 1978, 134, 145). It provides an excuse for the villainous Aeneas Manston, the secret son of Miss Aldclyffe and steward of her estate, to fake evidence of his first wife's death in the fire so that he is free to marry Cytherea and to put off Edward's 
rival suit by arranging to make his family pay for their "negligence" by rebuilding the uninsured cottages (Hardy [1871] 2003, 185). The whole plot takes root in this event. Since the "sole object of this narration," Hardy writes, is "to present in a regular series the several episodes and incidents which directly helped forward the end, and only these, every contiguous scene without this qualification is necessarily passed over" (69). All the episodes are meant to have the vividness of catching fire, linked together by a filament that catches alight in our minds just as their insights strike characters like so many sparks and flames, as when Manston sees through to Cytherea's reasons for having him as steward and "the mere spark of life" turns "a bundle of perceptions [into] an organic whole" (185). Yet the fire also occurs because of a too-rapid induction from counted instances, a failure to consider the negative space built into such chains or to forecast long-run shifts in the data. After the conflagration, the Springrove family finds that the insurance on the cottages has lapsed, the office having demurred to cover "thatched premises ... on account ... of the uncertainty and greatness of the risk of thatch undetached" (179). Fire insurance and the typically higher premiums for thatched premises had been the subject of parliamentary inquiry in early 1867, prior to Hardy's return from London to Dorchester (House of Commons 1867, 195, 57). Ignorance of such facts, the fruit of aggregate experience, is as much the target of satire as the unwillingness to count beyond three.

If the latter half of the novel reverses Farmer Springrove's error and showcases how crimes can be solved at both poles of serial thinking — by aggregating logical proofs and numerical probabilities and by attending to material marks and traces - it does so with an eye on the more catching conclusions that are visible off to the side. As Hardy moves his novel into the measured grooves of serial thinking, he does so by acknowledging the constant lure of a rival epistemologyof chance and coincidence, of intuition that proceeds preternaturally, not by logic. The novel's characters undergo tests of their sensitivity to serial thinking, their ability to infer based on patterns and departures from the norm, rather than by ascribing strange events to coincidence. During the strange night at Knapwater in which Miss Aldclyffe persists in trying to embrace her employee, Cytherea hears the alternating sounds of a waterfall and a water pump that constantly echo in the novel - a coachman earlier proclaims "something awful in the regularity of that sound" (Hardy [1871] 2003, 60). But she also hears another sound, "a very soft gurgle or rattle - of a strange and abnormal kind - yet a sound she had heard before at some past period of her life-when, she could not recollect" 
(87). A dog in the room starts whining: "One logical thought alone was able to enter her flurried brain. The little dog that began the whining must have heard the other two sounds even better than herself. He had taken no notice of them, but he had taken notice of the third. The third, then, was an unusual sound" (87). Miss Aldclyffe wakes up and "dismissed the third noise as something which in all likelihood could easily be explained, if trouble were taken to inquire into it" (88). But Cytherea turns out to be recursively correct. These were the dying sounds of Miss Aldclyffe's father in the room overhead. "Then I heard him!" she later exclaims. "A sound I had heard once before in my life - at the death-bed of my mother. I could not identify it—-though I recognised it" $(94,95)$. Cytherea here "parodies the elimination and deduction technique of a detective mystery, a Sherlock Holmes whose observations are as much more sensuous than his as they are inconclusive" (Bayley 1978, 134).

There are variations in how characters adjudicate information —old and new, fast and slow - along the lines of serial thinking. Edward, on one occasion, is said to have "reached the period in a young man's life when episodic pasts ... have begun to accumulate, and to bear a fruit of generalities; his glance sometimes seeming to state, 'I have already thought out the issue of such conditions as these we are experiencing.' At other times he wore an abstracted look: 'I seem to have lived through this moment before" (Hardy [1871] 2003, 31). Once on the trail of Manston, he deploys the "intellectual feat of suspending one's judgment ... though not without the penalty of watchful effort" (334), incidentally hewing to The Art of Reasoning's counsel for judgment (Neil 1853, 32). Still, there are moments when he is "too impatient to pursue his investigation carefully and inductively" (Hardy [1871] 2003, 251). Cytherea, in a gendered reversal of such inductive nonchalance, often has thoughts and emotions that "tak[e] up entirely new ground; as when gazing just after sunset at the pale blue sky we see a star coming into existence where nothing was before" (34). But it also seems "only natural that she should, by degrees, be unable to separate the discovery [of Manston's criminality], which was matter of fact, from the suspicion of treachery on her husband's part, which was only matter of inference" (255).

Serial thinking is key to unraveling the plot, whose crux is whether the woman Manston is palling around with (in contravention of his marriage to Cytherea) is his first wife, Eunice-declared dead in the fire-or an impostor. Edward, Cytherea, and Cytherea's brother Owen investigate Manston by examining newspaper records of the fire and by tracking down his old haunts and 
acquaintances, motivated by "how much more probable it seems that she should have escaped than have been burnt" (247). Cytherea thinks that two items of data cannot fit together, a photograph of Manston's supposed wife with black eyes and a poem Manston penned to Eunice of "azure eyes" (297, 308-9). Owen spies on Manston and the new woman in church and itemizes the details that make her "easily recognisable from the photograph" without the final confirmation of her eye color: "In opposition to the suspicion which one odd circumstance had bred in his sister concerning this woman, all ostensible and ordinary proofs and probabilities tended to the opposite conclusion" (312). But Cytherea's hunch is again correct, and Owen comes to the "conviction that the woman was an impostor" (315) through a numerical weighing of three items of evidence "in consequence" and two "in spite of" (314).

The twin operations of serial thinking are further at work in the novel's denouement, leading to the conviction of Manston and the marriage of Edward and Cytherea. With a more complete set of data in view, numbers and step-by-step insights dominate at first. Three individuals - Miss Aldclyffe, the impostor-wife Anne Seaway, and a "detective employed by Mr. Raunham to sift this mystery" (351) — stalk Manston while he reburies Eunice's body. Finally, this is a question of splitting hairs, quite literally. The detective compares strands to verify that the body is Eunice's, while "a probable and natural sequence of events and motives explanatory of the whole crime - events and motives shadowed forth by the letter, Manston's possession of it, his renunciation of Cytherea, and instalment of herself_-flash[ed] upon [Anne's] mind with the rapidity of lightning" (352). We count off Anne's itemized "logical inferences" (348) about the other watcher of Manston in the dark and follow similar steps in guessing the outcome of Edward's "second thoughts" about a "shabby man in a smock-frock," Manston disguised as a laborer $(357,356)$.

Yet there is still occasion for material inference to play its part as the group tracks the fleeing criminal. They have information that he has crossed a stile and find there "a heap of half-hardened mud" on which is "distinctly imprinted the form of a man's hand, the buttons of his waistcoat, and his watch-chain, showing that he had stumbled in hurrying over the stile, and fallen there" (355). They have a similar clue from a shepherd, who tells them that "wherever a clear space three or four yards wide ran in a line through a flock of sheep lying about a ewelease, it was a proof that somebody had passed there not more than half-an-hour earlier" (355). These details rescue the folk epistemology that should, as Hardy 
points out, have prevented that fire. Eventually, Manston is captured and taken away in a cart that is marked with the sort of long-run data that, in addition to logical-numerical steps, helped unmask his crimes: "Old and dry mud-splashes from long-forgotten rains disfigured its wheels and sides; the varnish and paint had been scratched and dimmed; ornament had long been forgotten in a restless contemplation of use" (361).

Even Farmer Springrove attains a more learned position about long-run series and expectations, coming a long way from the naive "Who expects a fire?" (179):

\footnotetext{
“Ah, Baker, we say sudden death, don't we. But there's no difference in their nature between sudden death, and death of any other sort. There's no such thing as a random snappen off of what was laid down to last longer. We only suddenly light upon an end - thoughtfully formed as any other - which has been existen at that very same point from the beginnen, though unseen by us to be so soon."

"It is just a discovery to your own mind, and not an alteration in the Lord's."

"That's it. Unexpected is not as to the thing, but as to our sight." (362)
}

This folksy reversal of Venn's ([1866] 1888, x) view of logic as taking cognizance "of laws of things and not of the laws of our own minds in thinking about things" is also a canny reflection on the serial structure and limits of predictive knowledge.

From the outset Hardy's representational project can be profitably viewed according to the terms laid out by serial thinking in both its material and its numerical versions. Considering warrants for knowledge in settings that involve couch-grass fires and weather-beaten boundary stones and ominously faded signs, Hardy spotlights how even simple inferences might rely on long-run iterations. Setting these depictions against scenes of numerical proofs and step-bystep inferences, he brings logical contexts into contact with felt complexities. The passing reference to the logic of sunrise transforms the trope to engage the problem of induction and to call out its affective, tactile dimensions, connecting the small-scale counting that starts off an experience-watching the sun rise once, twice, thrice — to the uncountable aggregates that ground inference.

\section{Genres of Induction: The Problem of (Reference) Class}

These features of Desperate Remedies that combine discrete enumeration and long-run blends thus address and complicate key concerns of nineteenth-century logic: whether and how series can be used to make inferences and how the problem of establishing appropriate boundaries to series can engender faulty infer- 
ences and thwart prediction. Serial thinking provides insight into the novel's representational modes and, as I discuss below, illuminates a question that was of inchoate professional concern to Hardy and remains valuable to literary studies: the question of genre. Indeed, serial thinking can be directly related to a problem in inductive logic - how we delineate the relevant classes about which judgments can be made - that is also pertinent to generic classification. This "reference class problem" goes back to Venn (Eden 1998, 20-22). It is "generated by the fact that any particular event belongs to various sets," so the probability of a "single proposition . . may be classified in various ways, yet its probability can change depending on how it is classified" (Hájek 2007, 564, 565). To adopt Venn's ([1866] 1888, 213-34) melancholy example, the probability that a fifty-one-year-old "consumptive Englishman" will live to sixty depends on identifying the relevant reference class and avoiding undue heterogeneity within that class: people over fifty? Victorian gentlemen? consumptives? A similar problem besets determinations about literary texts, especially where genre is concerned. The probability that a given text will contain an allusion to the Aeneid; bear a two-word title; include two characters with the same name; or exhibit any other thematic, lexical, semantic, affective, or structural property all depends on the reference class. Are we reading a sensation novel? a text by Hardy? a novel published by Tinsley Brothers? any Victorian text over 100,000 words?

Serial thinking thus elaborates both theoretical and empirical puzzles about genre classification, and as such it dramatizes the generic predicament that preoccupies Hardy's early sequence of novels, starting with Desperate Remedies. In this section I argue that Hardy's frustration about having to delineate an appropriate genre or reference class, artificially marking out an area in a shifting terrain, is enacted in the text's representations of class: its figures for logical groups, social arrangements, and generalizing processes. Further, I contend that the discourse of logical classes on which the novel draws has repercussions for methodological debates about genre. The contemporary intuition that classes are alterable, subject to fluid redrawing and recombination when seen at different levels of explanation, owes much to the nineteenth-century materials already instantiated in Hardy's early work.

The well-rehearsed publication history of Desperate Remedies commands new significance in this light. ${ }^{5}$ Hardy at first shopped to Macmillan the manu-

5. See especially Dalziel 1995; Millgate 2004, 100-111, 116-17, 120-25. 
script of a now-lost novel titled The Poor Man and the Lady, written in 1867-68. He justified the text's frank approach to class by noting that "the upper classes of society have been induced to read, before any, books in which they themselves are painted by a comparative outsider" (Hardy 1978, 7). ${ }^{6}$ After a string of rejections, Hardy recast the novel as Desperate Remedies in 1869-70, subordinating class satire to romance and crime and using his pithy title to announce a similarity to others in the Tinsley Brothers stable, which almost read like a plot sketch: Francis Brough's Hidden Fire (1867), Annie Thomas's High Stakes (1867) and False Colours (1869), Edmund Yates's The Forlorn Hope (1867) and A Righted Wrong (1870), and Frances Cashel Hoey's Falsely True (1870).

Hardy $(1978,12)$ endorsed this reference class for his novel, claiming in response to critical reviews that "my object in the story having been simply to construct an intricate puzzle which nobody should guess till the end," the characters became "mere puppets or pegs to weave the work upon-without reality or character enough in them to warrant their being denounced for want of moral attributes." "Yet such an apology for the crude adjustments needed to claim generic affiliation implies that these changes occupy only one stylistic stratum. The patterns of serial thinking occupy another level of representation that works loose from the novel's sensation components and is routinely on offer in the texts that share an "underlying continuity" (Millgate 2004, 133) with the Poor Man manuscript: Hardy's second and third novels, Under the Greenwood Tree (1872) and A Pair of Blue Eyes (1873); the serialized novella never collected in later editions, "An Indiscretion in the Life of an Heiress" (1878); and the poems reworked into Desperate Remedies. A representative example will suffice. The gamekeeper in Under the Greenwood Tree hangs his hat on a nail "arched by a rainbowshaped stain," and his house has the following "peculiarity": "The window-board was curiously stamped with black circles, burnt thereon by the heated bottoms of drinking-cups, ... the result giving to the ledge the look of an envelope which has passed through innumerable post-offices" (Hardy [1872] 1998, 73-74).

The continuity of these representational markers, as Hardy's manuscripts worked their way through what must have felt like innumerable publishing offices, establishes a stylistic feature that persists across his work in defiance

6. Letter to Alexander Macmillan, July 25, 1868.

7. I draw these titles from Bassett 2016.

8. Letter to Malcolm Macmillan, August 17, 1871. 
of genre's pendulum swing. These recurrent motifs make it less incongruous that the title page of Under the Greenwood Tree (subtitled A Rural Painting of the Dutch School) would blithely advertise itself as "by the author of Desperate Remedies." Hardy pointed to reviews of his first novel to promote the next (Millgate 2004, 127), even though it is a generic volte-face, "entirely a story of rural life, [in which] the attempt has been to draw the characters humorously, without caricature" (Hardy 1978, 11). ${ }^{9}$ These serial patterns dramatize the problem of establishing a generic identity from a small sequence of instances - counting up from Desperate Remedies (one) to Under the Greenwood Tree (two) to A Pair of Blue Eyes (three) to Far from the Madding Crowd (four). They do so partly by pointing to the mental activity (what Neil [1853, 24-25] calls "generalization") that draws higher-order conclusions from single instances or cases, that "collects, arranges, compares, and colligates" (31).

The class elements of The Poor Man and the Lady may have been smoothed out in resultant texts like Desperate Remedies and "Indiscretion," although examining these aspects remains fruitful. ${ }^{10}$ But attention to more abstract figures and processes of classification keeps some satirical intent alive, marking the difference between Hardy's ([1871] 2003, 103) own view_in the lapidary observation that "social definitions are all made relatively: an absolute datum is only imagined" - and that of his characters, who act according to the feeling (ascribed to Owen) that "humanity ... was rather divided into distinct classes than blended from extreme to extreme" (18). We witness a scene of sorting that assures Manston's selection as steward from the "whole heap of letters, testimonials, and references" (107); a confusion between "third-class" and "second-class" carriages, which causes Manston to miss the arrival of his wife, whom he terms a "third-rate actress" $(161,155)$; and a sifting through likenesses of his wife to doctor Edward's intercepted letter by inserting "the one most resembling [the photograph] abstracted from the letter in general tone, size, and attitude" (307). In a story motivated by cross-class desire and tensions between landholders, stewards, and tenants, there are incessant confusions about status and boundaries, as when Miss Aldclyffe does not realize the possibility that Edward's education has granted him a "developed man's unorthodox opinion about the subordination of classes" (193).

9. Letter to Macmillan and Company, August 7, 1871.

10. See especially Ousby 1984; Widdowson 1989, 129-54. 
When read in conjunction with his early publishing struggles and the class consciousness they entailed, these motifs yield a complex picture of the novel's social commitments. Hardy could be seen to participate in the conventions of a genre that, as Jonathan Loesberg (1986) has argued, developed in the ideological matrix of Victorian parliamentary reform to dramatize class dissolution (and fear thereof). In sensation novels "the image of a loss or shift of class identity" must paradoxically be "class[ed] as accidental" in plots "constructed on the principle of inevitable sequence" $(130,117)$. Yet if Hardy engages in this sort of mystification, Desperate Remedies also adumbrates the critical complexities that others have found in novels like Jude the Obscure (1895), which threads together social inclusion and exclusion (Jaffe 2010), rigid legal norms and plastic social arrangements (Kornbluh 2015). Hardy includes several of the framing devices of "bourgeois norms" that enact the "estrangement from and attachment to a culture that relies on their invisibility" (Jaffe 2010, 386), cannily jumping boundaries even as he establishes them: "a glass pane in the partition dividing [the parlour] from the bar" (Hardy [1871] 2003, 36); Cytherea and Edward catching one another's images reflected in a river (237-38); Manston's face against the glass of Cytherea's hiding place in Casterbridge (357-58). He is as attuned to the delineation of classes, that is, as he is to their dissolution. Serial thinking can usefully bring these approaches together. Relying on Venn's fluctuating series, we can see how the danger of making judgments on the basis of ill-defined reference classes (an inductive-logical problem) is akin to making judgments about one person based on hasty class designations (a social problem). Figuring how such boundaries are etched, blurred, dissolved, and redrawn, Hardy at once upholds and erases the geometries of class, like Venn revealing "class" as a problem of shifting frames and mutable determinations.

The novel's ingredients, both formal and thematic, thus mingle according to what Jacques Derrida (1980, 59), an archenemy of stable conceptions of genre, calls a "principle of contamination, a law of impurity." Such generic commingling, everywhere on offer in Hardy, has been seen as central to renovations of genre as a dynamic concept: in special issues of New Literary History (Cohen 2003) and PMLA (Dimock and Robbins 2007), in The Work of Genre (Warhol 2011), and in David Duff's (2009, 160-91) account of the "combinatorial method" in romantic era genre experiments. Many of these accounts have recourse to figures of spatial overlapping or the blurring of logical sets, showing how generic elements can be "juxtaposed rather than integrated" or "transformed and assimi- 
lated" (178). Nineteenth-century thinking about sets and reference classes can thus clarify the intrinsic dynamism of literary genres - and sharpen the difficulties that genre concepts pose- by showing how judgments about sets that are mutable and/or overlapping are akin to empirical determinations about the categories of literary objects across differing historical circumstances. The figurative and conceptual resources of a resistance to bounded sets are also vital, I maintain, as we consider the uses of a quantitative episteme in literary studies that advances genre claims using the tools of "logic" (in the looser sense that includes the forebears of statistics and computer science: Venn's frequentist probability and George Boole's logical operators).

Wai Chee Dimock's work provides a compelling case study for comparing dynamic genres to the problem of reference classes. I take it as shorthand for the flexible vision of logic that forms a crucial if often-unstated element of recent work on genre. Dimock's $(2006,4,73)$ attention to generic blending is a key element of her program to recast literature as the "home of nonstandard space and time," where unexpected filiations are brought out by refusing to see literature as "discrete." She adverts to a logico-mathematical language to theorize genre, which she sees "less as a law, a rigid taxonomic landscape, and more as a self-obsoleting system, a provisional set that will always be bent and pulled and stretched by its many subsets" (73). Generic similarity is "probabilistic and distributional" (74), and set membership is open-ended: "The literary field is still incomplete, its kinship network only partly actualized, with many new members still to be added" (79). The connection to Venn's description of mutable, openended types - and to his later diagrams of how logical sets blend and overlap (Venn 1889) - is striking, as is the elision of this founding discourse. One of Dimock's $(2006,78,86)$ choice images for theorizing dynamism is fractal geometry, where a pattern's "robustness across scales" can be used to model "the novel as a linguistic sponge ... picking up the poetic genre, steeping it in a different medium, and preserving it only in percentage." The claims for genre dynamism are powerfully stated, but this valorization of "scalability" (Dimock 2011, 97) does not necessarily install a conception of genre that is "robust," at least in the philosophical sense of describing a scientific account that operates coherently across levels of explanation (Wimsatt 2007). For all that fractal patterns can figure how Hardy's poetic material is preserved in his first novel, for instance, they cannot provide a model that works at every scale.

If the concept of genre is set to become more central as quantitative meth- 
ods gain prominence, the nature of generic dynamism will be key. As Stephen Owen $(2007,1393)$ puts it, "Wherever someone wants to count something . . . limited taxonomic sets must be made to enable the enterprise." Pointing out the constitutive tension between genre's irregular instances and its more regular aggregates would put work on genre's local complexity in conversation with work on its global pattern. In the latter camp I have in mind approaches like "distant reading" (Moretti 2013) and "macroanalysis" (Jockers 2013), digital methods that map, detect, and visualize generic evolution at expansive scales. Since the categories essential to such work can be multiply, mutably decided, subject to what Ted Underwood and colleagues (2013) call both "historical heterogeneity" and "internal heterogeneity" - evolution over time and variation within textual borders - some initial decisions about parameters will typically be necessary.

The discourse of "classes" and "sets" drawn from nineteenth-century studies in logic and probability offers a useful way to approach these problems, because it relates to both empirical and theoretical assessments of genre. Venn's thought still provides a mooring point for critiques of probability and statistical reasoning (Hájek 2007). Indeed, there is some irony in the fact that the nineteenth century, a fertile ground for quantitative literary study, saw the opening of a sustained debate about the understructure of statistical groups that fundamentally sustain (but complicate) data analysis. Venn's work also offers a rationale for the metaphors of generic dynamism. If quantitative models are open to the critique that they are mediated by the "deep structures" of the history they purport to decode, relying on the "figurative processes" of data visualization that mask a "disjunction between the shapes of the new history and the numbers . . of which these forms are composed" (Wickman 2014, 2, 3), it matters whether the figures we select to think about genre involve bounded and overlapping sets, patterns that spiral across scales, or particles that mix according to random collisions (in another of Dimock's [2011, 101] images). Literary qualities like genre and subgenre can be instantiated by figures and images, some of which have shifting historical senses, and not only by machine-readable elements of text, diction, syntax, quantity, and so on.

Mining notions in nineteenth-century philosophy - and in literary narratives like Hardy's that thematize and complicate them in distinctive ways - can sharpen our theories of literary inference and classification. The process by which we recurrently posit a stable concept of genre only to disrupt or hybridize it is a 
process internal to genre, seen as the mutable aggregate order that emerges from individual disorder. The problem of selecting the appropriate reference class - in inductive problems as in generic determinations - requires that we decide, provisionally, on the class of instances about which we infer. Genre is a decision theory problem: unless our aim is simply to reiterate the complexity of any given generic designation, we will always be straining against the necessity of such determinations. Dimock $(2011,102)$ writes of the "different reference frames" that apply at various scales. John Frow $(2007,1631)$ notes that we must "decide, from a limited range of possibilities, which frame yields a preferred reading." Quantitative analysis has proven fertile in articulating the historical evolution of genres, but we also need to think in a fine-grained way about what generic hybridization is doing - to form, narrative, representation - in single texts and emerging oeuvres. We might thereby restore to literary work that sense of discrete yet open-ended iteration glimpsed in the auroral logic with which I began.

Narrative works against — in the senses both of defying and of graphing data; it keeps track of relatively stable individuals and has an eye on the uneven flux of aggregate information. Exploiting narrative's scalar tensions, Hardy dramatizes the problem of reference classes both to smear class boundaries and to shelter a sense of self within the coldness of ineluctable categories. Of Cytherea, he writes that "to attempt to gain a view of her . . . from a measured category, is as difficult as to appreciate the effect of a landscape by exploring it at night with a lantern" (Hardy [1871] 2003, 12). Manston's suicide note, on the contrary, describes him as returning to a "normal condition": the "long race of men" consists "mainly [of] dead men, who have scarcely ever been otherwise" (370). Hardy draws an immense horizon around his characters, reflecting that "the question how their lives would end seemed the deepest of possible enigmas" to Cytherea and Owen, even though "to others who knew their position equally well with themselves the question was the easiest that could be asked._- 'Like those of other people similarly circumstanced" "(17). In the future anterior mode, Cytherea muses on how her friends' judgments will "never realize that it was my single opportunity of existence . . . which they are regarding; they will not feel that what to them is but a thought, easily held in those two words of pity, 'Poor girl,' was a whole life to me" (236). Her thought, prosed out of the sonnet "She, to Him II," could stand as a forlorn complaint lodged by Hardy's $(1982,19)$ early work against his later productions: 
Perhaps, long hence, when I have passed away, Some other's feature, accent, thought like mine, Will carry you back to what I used to say.

Acknowledging that "unquencheable expectation, which at the gloomiest time persists in inferring that because we are ourselves, there must be a special future in store for us, though our nature and antecedents to the remotest particular have been common to thousands," Hardy ([1871] 2003, 17) both mocks and acknowledges the blinkered inference of the small view, the building block of narrative, the loose cornerstone of a literary career, the induction that cannot glimpse an emerging generic totality. In the sunrise of the novel, today is like every day, and anything could happen.

Daniel Williams is a junior fellow at the Harvard Society of Fellows. He has published articles on Thomas Hardy, John Ruskin, and Gerard Manley Hopkins and on twentieth- and twenty-first-century British and South African literature. He is currently working on a book about uncertainty in the nineteenth-century British novel in connection with developments in science, philosophy, and the law.

\section{Works Cited}

Bassett, Troy J. 2016. At the Circulating Library: A Database of Victorian Fiction, 1837-1901. Victorian Research Web. www.victorianresearch.org/atcl.

Bayley, John. 1978. An Essay on Hardy. Cambridge: Cambridge University Press.

Butler, Joseph. (1736) 1740. The Analogy of Religion, Natural and Revealed, to the Course and Constitution of Nature. London: John and Paul Knapton. Citations refer to the 1740 edition.

Cohen, Ralph, ed. 2003. “Theorizing Genres.” Special issue, New Literary History 34 , nos. $2-3$.

Coleridge, Samuel Taylor. 1990. Table Talk. Edited by Carl Woodring. 2 vols. Vol. 14 of The Collected Works of Samuel Taylor Coleridge. Princeton, NJ: Princeton University Press.

Dalziel, Pamela. 1995. "Exploiting the Poor Man: The Genesis of Hardy's Desperate Remedies." Journal of English and Germanic Philology 94, no. 2: 220-32.

Daston, Lorraine. 1998. Classical Probability in the Enlightenment. Princeton, NJ: Princeton University Press.

Derrida, Jacques. 1980. “The Law of Genre.” Translated by Avital Ronell. Critical Inquiry 7, no. 1: 55-81.

Dimock, Wai Chee. 2006. Through Other Continents: American Literature across Deep Time. Princeton, NJ: Princeton University Press. 
2011. “Migration across Genres.” In Warhol 2011, pars. 96-128.

Dimock, Wai Chee, and Bruce Robbins, eds. 2007. "Remapping Genres." Special issue, PMLA 122, no. 5.

Duff, David. 2009. Romanticism and the Uses of Genre. Oxford: Oxford University Press.

Eden, Berna K1liç. 1998. John Venn's Evolutionary Logic of Chance. Berlin: MaxPlanck-Institut für Wissenschaftsgeschichte.

Frow, John. 2007. “'Reproducibles, Rubrics, and Everything You Need': Genre Theory Today." PMLA 122, no. 5: 1626-34.

Hacking, Ian. 1990. The Taming of Chance. Cambridge: Cambridge University Press. - 2006. The Emergence of Probability: A Philosophical Study of Early Ideas about Probability, Induction, and Statistical Inference. 2nd ed. Cambridge: Cambridge University Press.

Hájek, Alan. 2007. "The Reference Class Problem Is Your Problem Too.” Synthese 156, no. 3: $563-85$.

Hardy, Thomas. (1871) 2003. Desperate Remedies. Edited by Patricia Ingham. Oxford: Oxford University Press. Citations refer to the 2003 edition.

- (1872) 1998. Under the Greenwood Tree. Edited by Tim Dolin. London: Penguin. Citations refer to the 1998 edition.

. (1874) 2000. Far from the Madding Crowd. Edited by Rosemarie Morgan and Shannon Russell. London: Penguin. Citations refer to the 2000 edition.

- 1978. The Collected Letters of Thomas Hardy. Vol. 1. Edited by Richard Little Purdy and Michael Millgate. Oxford: Clarendon.

- 1982. The Complete Poetical Works of Thomas Hardy. Vol. 1. Edited by Samuel Hynes. Oxford: Clarendon.

House of Commons. 1867. "Report from the Select Committee on Fire Protection, Together with the Proceedings of the Committee, Minutes of Evidence, and Appendix." Sessional Papers, Reports of Committees, vol. 10, 1-287.

Hume, David. (1748) 2000. An Enquiry concerning Human Understanding: A Critical Edition. Edited by Tom Beauchamp. Oxford: Clarendon. Citations refer to the 2000 edition.

Jaffe, Audrey. 2010. “"Outside the Gates of Everything': Hardy's Exclusionary Realism." NOVEL: A Forum on Fiction 43, no. 3: 381-400.

Jockers, Matthew. 2013. Macroanalysis: Digital Methods and Literary History. Urbana: University of Illinois Press.

Kornbluh, Anna. 2015. "Obscure Forms: The Letter, the Law, and the Line in Hardy's Social Geometry." NOVEL: A Forum on Fiction 48, no. 1: 1-17.

Laplace, Pierre-Simon. (1814) 1902. A Philosophical Essay on Probabilities. Translated by Frederick Wilson Truscott and Frederick Lincoln Emory. New York: Wiley. Citations refer to the 1902 edition.

Loesberg, Jonathan. 1986. "The Ideology of Narrative Form in Sensation Fiction." Representations 13: 115-38. 
Mill, John Stuart. (1843) 1973. A System of Logic, Ratiocinative and Inductive: Being a Connected View of the Principles of Evidence, and the Methods of Scientific Investigation. Edited by John M. Robson. 2 vols. Toronto: University of Toronto Press. Citations refer to the 1973 edition.

Millgate, Michael. 2004. Thomas Hardy: A Biography Revisited. Oxford: Oxford University Press.

Moretti, Franco. 2013. Distant Reading. London: Verso.

Neil, Samuel. 1853. The Art of Reasoning: A Popular Exposition of the Principles of Logic, Inductive and Deductive, with an Introductory Outline of the History of Logic. London: Walton and Maberley.

Ousby, Ian. 1984. "Class in Desperate Remedies." Durham University Journal 76, no. 2: 217-22.

Owen, Stephen. 2007. "Genres in Motion.” PMLA 122, no. 5: 1389-93.

Porter, Theodore M. 1986. The Rise of Statistical Thinking, 1820-1900. Princeton, NJ: Princeton University Press.

Scarry, Elaine. 1994. Resisting Representation. New York: Oxford University Press.

Underwood, Ted, Michael L. Black, Loretta Auvil, and Boris Capitanu. 2013. "Mapping Mutable Genres in Structurally Complex Volumes." Proceedings of the 2013 IEEE International Conference on Big Data, arxiv.org/abs/1309.3323.

Venn, John. (1866) 1888. The Logic of Chance: An Essay on the Foundations and Province of the Theory of Probability. 3rd ed. London: Macmillan. Citations refer to the 1888 edition.

- 1870. On Some of the Characteristics of Belief, Scientific and Religious: Being the Hulsean Lectures for 1869. London: Macmillan.

- 1889. The Principles of Empirical or Inductive Logic. London: Macmillan.

Wall, Byron E. 2006. "John Venn's Opposition to Probability as Degree of Belief." Studies in History and Philosophy of Science 37, no. 4: 550-61.

Ward, Megan. 2011. "The Woodlanders and the Cultivation of Realism." Studies in English Literature 1500-1900 51, no. 4: 865-82.

Warhol, Robyn, ed. 2011. The Work of Genre: Selected Essays from the English Institute. Cambridge, MA: English Institute and American Council of Learned Societies, hdl.handle.net/2027/heb.90055.0001.001.

Wickman, Matthew. 2014. "Robert Burns and Big Data; or, Pests of Quantity and Visualization.” Modern Language Quarterly 75, no. 1: 1-28.

Widdowson, Peter. 1989. Hardy in History: A Study in Literary Sociology. London: Routledge.

Wimsatt, William C. 2007. Re-engineering Philosophy for Limited Beings: Piecewise Approximations to Reality. Cambridge, MA: Harvard University Press. 